\title{
Lung transplant in a recipient with tracheal bronchus
}

Duvuru Ram ${ }^{1}$, Mark O'Carroll ${ }^{1}$, Peter Alison ${ }^{1}$, and Amul Sibal ${ }^{1}$

${ }^{1}$ Auckland City Hospital

April 28, 2020

Abstract
We describe the intra-operative surgical management of tracheal bronchus encountered in a lung transplant recipient. 


\section{Figure legends:}

$1 \mathrm{~A}$ - Computed tomography scan coronal view of the right tracheal bronchus (Yellow arrow)

1B - Explanted lung from the recipient with right tracheal bronchus (Yellow arrow)

2 - Postoperative surveillance bronchoscopy image of reconstructed right bronchus

\section{Author contributions:}

DR, PMA, AKS : Concept, design, data drafting, reviewing, editing, approval of final manuscript. MOC : Critical revision of article, editing, approval of final manuscript.

\section{References:}


1. Doolittle AM, Mair EA. Tracheal bronchus: Classification, endoscopic analysis, and airway management. Otolaryngology - Head and Neck Surgery. 2002;126(3):240-3.

2. Jamil A, Soos MP. Tracheal Bronchus. In: StatPearls [Internet]. Treasure Island (FL): StatPearls Publishing; 2020 [cited 2020 Jan 28]. Available from: http://www.ncbi.nlm.nih.gov/books/NBK547715/

3. Mendogni P, Tosi D, Rosso L, Palleschi A, Righi I, Montoli M, et al. Lung Transplant From Donor With Tracheal Bronchus: Case Report and Literature Review. Transplantation Proceedings. 2019;51(1):239-41.

4. Magee MJ, Griffith BP, Armitage JM. Management of a tracheal bronchus in a pediatric lung transplant recipient. Ann Thorac Surg. 1994;58(1):229-31.
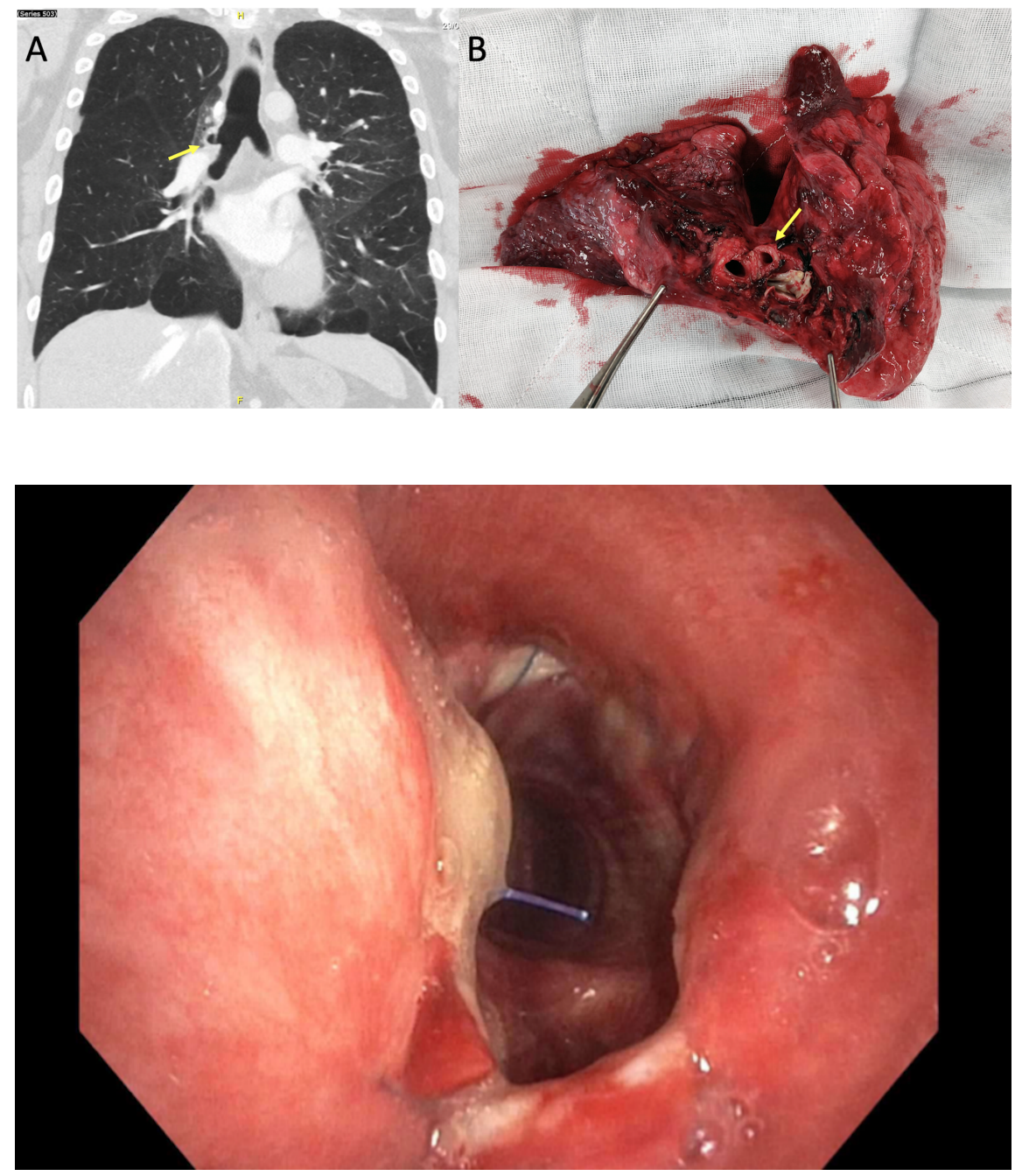